\title{
Cystic fibrosis in adolescents and adults
}

\author{
A R L PENKETH, A WISE, M B MEARNS, M E HODSON, J C BATTEN
}

From the Department of Cystic Fibrosis, Brompton Hospital, London

ABSTRACT Three hundred and sixteen patients with cystic fibrosis were seen at the Brompton $\stackrel{\omega}{\stackrel{\omega}{*}}$ Hospital during $1965-83 ; 178(56 \cdot 3 \%)$ of them were male and 136 female, and their ages ranged $\overrightarrow{\vec{x}}$ from 12 to 51 years. Most patients presented in infancy with respiratory symptoms and mal- $\vec{N}$ absorption, but $19(6 \%)$ were diagnosed in adult life, three in their 30s. Pulmonary disease was. - . almost universal $(99.7 \%)$, being responsible for $97 \%$ of all deaths and three quarters of hospital N admissions. All patients had developed a productive cough by the age of 21 and over half before the

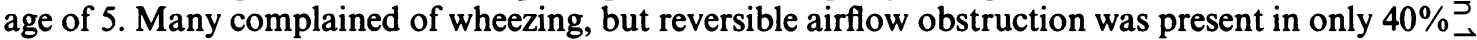
of those tested. Minor haemoptysis was very common (62\%), but major episodes less so (10\%). $ᄃ$ Pneumothorax was seen in 61 cases $(19 \%)$, and was often recurrent. Some irreversible airflow obstruction was present in all patients with pulmonary disease. Two patients have been followed for $\vec{\varphi}$ over 20 years without showing appreciable decline in lung function. Thirty five patients $(11 \%)$ had. no symptoms of malabsorption. Acute meconium ileus equivalent was seen in $16 \%$ and a chronic partial obstruction with episodic symptoms in a further $19 \%$. Diabetes mellitus developed in $36 \sum_{\Sigma}$ patients, 13 of whom were insulin dependent. Hepatomegaly was common (29\%), often occurring without abnormal results in biochemical tests of liver function; only $1 \%$ of patients developed $\mathscr{\varrho}^{\circ}$ portal hypertension with varices and ascites. Skin reactions to at least one common allergen, includ- $\varrho$ ing Aspergillus fumigatus, were positive in $70 \%$, but very few patients suffered from hay fever or $\overrightarrow{\overrightarrow{0}}$ eczema. One hundred and twenty one patients have died, $97 \%$ from infection or other pulmonary 3 complications, and 195 were alive in December 1983 (mean age 23 years). Seventy eight per cent of patients were in full time education or full or part time employment, or were housewives, and only 41 were unemployed for reasons for health. Many patients are married and 10 women have borne $\vec{\circ}$ children. Most patients were admitted to hospital only three or four times during the period of follow up and 50 individuals $(16 \%)$ have never been in hospital at all. The improvement in: prognosis and quality of life for adults with cystic fibrosis should encourage a positive attitude in those who care for them.

Many thoracic physicians now manage patients with cystic fibrosis. Most patients who present in infancy or childhood now survive into adult life, ${ }^{1}$ while some cases at the mild end of the clinical range are now being diagnosed in middle age. ${ }^{2} \mathrm{~A}$ special unit for the care of adolescents and adults with cystic fibrosis has existed at the Brompton Hospital for 20 years. Computerisation of patient records provided an opportunity to review the experience of this unit.

\section{Methods}

The notes of all patients attending the Brompton

Address for reprint requests: Dr M E Hodson, Department of Cystic Fibrosis, Brompton Hospital, London SW3 6HP.

Accepted 9 February 1987
Hospital cystic fibrosis unit during 1965-83 were reviewed. All cases had had the diagnosis of cystico fibrosis confirmed at the Brompton Hospital by the finding of a sweat sodium concentration of $>70^{\circ}$ $\mathrm{mmol}(\mathrm{mEq}) / 1$ by pilocarpine iontophoresis. ${ }^{3}$ Infor- $\tilde{O}$ mation obtained from the hospital notes and from ${ }_{\mathcal{E}}^{N}$ interview in the case of surviving patients waso recorded on a standard questionnaire by one of us (AW) and entered into a data storage program on $\mathrm{a}_{\bar{\Phi}}$ Prime 750 computer. The follow up period was until@ December 1983 or until death.

Information obtained on clinical examination and ${ }^{\circ}$ from laboratory results was noted for the first referral ${ }_{\Omega}^{\mathbb{P}}$ to the Brompton Cystic Fibrosis Unit and for the last outpatient visit before death or the last outpatient $\frac{}{\sigma}$ visit of 1983. Malabsorption was defined in terms of steatorrhoea; the patient's bowels were opened moreo 
frequently than normal, the stools often floated, and they were observed to be fatty. The Registrar General's classification of social class by occupation was used for both patients and their parents. Body weight was expressed as a percentage of predicted normal on the basis of tables from the Society of Actuaries (build and blood pressure study). ${ }^{4} \mathrm{FEV}_{1}$ and forced vital capacity (FVC) were recorded on a Vitalograph spirometer and peak expiratory flow (PEF) rate- the best of three attempts-on a Wright's peak flow meter. Results of all respiratory function tests were expressed as percentages of predicted normal values for age, sex, and height from tables published by Cotes. ${ }^{5}$ Some reversible airflow obstruction was considered to be present if the peak flow improved by more than $10 \%$ after inhalation of $200 \mu \mathrm{g}$ of salbutamol. Scores for symptoms such as cough or sputum were on a three point scale of mild, moderate, and severe. Laboratory data were recorded as the actual values. Skinprick tests for immediate hypersensitivity to common allergens (house dust mite, grass pollen, and Aspergillus fumigatus) were carried out in 233 cases with allergen solutions standardised by the immunology department of the Cardiothoracic Institute.

In some categories data were not available on all 316 cases, and here results were expressed as percentages of the patients for whom information was available. This leads to an overestimate where the unknown data were probably negative (for example, the incidence of serious complications), and here figures for known data and the whole series are given if they differ by more than $1 \%$.

\section{Results}

\section{PATIENTS AND PRESENTATION}

Overall, 316 patients with cystic fibrosis were seen at the Brompton Hospital from 1965 to the end of December $1983 ; 178$ of them $(56 \cdot 3 \%)$ were male and 136 female and their ages 12-51 years. Most were referred by paediatricians, in particular from the Hospital for Sick Children, Great Ormond Street, and Queen Elizabeth Hospital, Hackney, London; but $15 \%$ of our patients were referred by other physicians and $20 \%$ by their general practitioners. Most were in their late teens by the time of referral, but $23 \%$ were referred in their 20 s and four after the age of 30 years.

The diagnosis of cystic fibrosis was made in the first year of life in $48 \%$ and before the age of 5 in $77 \%$ of cases. Nineteen patients $(6 \%)$ were diagnosed after the age of 16, and three were not diagnosed until their 30 s, although all had had symptoms for at least 10 years. At the time of presentation most patients had either respiratory symptoms $(49 \%)$ or malabsorption $(60 \%)$ or both (table 1$)$.
Table 1 Symptoms and age at presentation in 316 patients with cystic fibrosis

\begin{tabular}{|c|c|c|}
\hline Symptom & $\begin{array}{l}\text { No }(\%) \text { of } \\
\text { patients* }\end{array}$ & $\begin{array}{l}\text { Mean age at } \\
\text { diagnosis }(y) \dagger\end{array}$ \\
\hline $\begin{array}{l}\text { Chest disease only } \\
\text { Malabsorption only } \\
\text { Chest disease and other } \\
\text { symptoms } \\
\text { Malabsorption and other } \\
\text { symptoms }\end{array}$ & $\begin{array}{r}68(22 \%) \\
102(34 \%)\end{array}$ & $\left.\begin{array}{l}9.2 \\
1.6 \\
5.9\end{array}\right\} * *$ \\
\hline
\end{tabular}

* Most patients presented with more than one symptom. +Mean for whole group 3.8 years.

$* *$ Significance of difference $\left(\chi^{2}\right.$ test $): p<0.001$.

In general those patients presenting with malabsorption alone (mean age at diagnosis 1.6 years) or failure to thrive (mean age $1 \cdot 1$ years) were significantly younger than those patients presenting only with respiratory symptoms (mean age at diagnosis 9.2 years; $p<0.001$ ). A third of all patients presented in infancy with failure to thrive; smaller numbers presented with meconium ileus $(4 \%)$ or rectal prolapse $(4 \%)$. Some patients $(17 \%)$ were brought to medical attention by the diagnosis of cystic fibroșis in a close relative.

\section{PULMONARY DISEASE}

Pulmonary disease was almost universal, 315 of the 316 patients being affected $(99 \cdot 7 \%)$. The first symp-

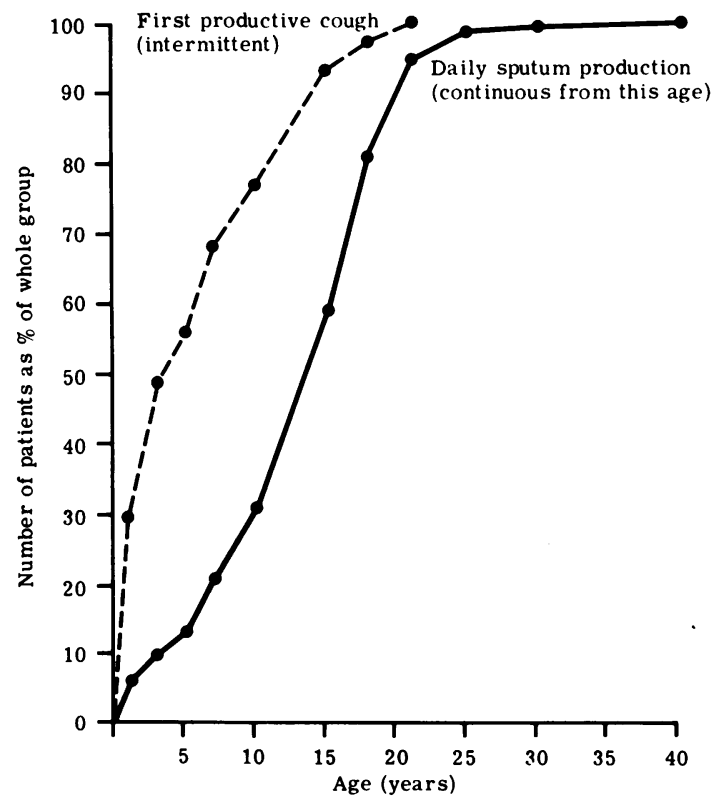

Fig 1 Cumulative numbers of patients with respiratory symptoms at particular ages. 
toms were experienced before the age of 5 in $63 \%$ and by the age of 21 in all patients (fig 1). Symptoms remained intermittent for up to 10 years in some cases. The predominant symptom was a productive cough (99.4\%); dyspnoea was also a common symptom $(80 \%)$, while $52 \%$ complained of wheezing. Despite the frequency of wheezing only $40 \%$ of the 268 patients tested had reversible airflow obstruction. Peak flow improved by $10-20 \%$ in 69 cases $(26 \%)$ and by more than $20 \%$ of baseline in 38 patients (14\%) after inhalation of salbutamol.

All patients with pulmonary disease have progressive airflow obstruction. Figures 2 and 3 show the mean and range of the values of $\mathrm{FEV}_{1}$ and FVC, recorded in 1983 for 191 patients, who were divided by age into one year cohorts. At all ages the FEV 1 was more severely affected than the FVC, but the range was wide and values greater than $100 \%$ were observed in one or two individuals at each age up to 28 years.

Ninety five patients had been followed for three years or more with spirometry. The two patients with

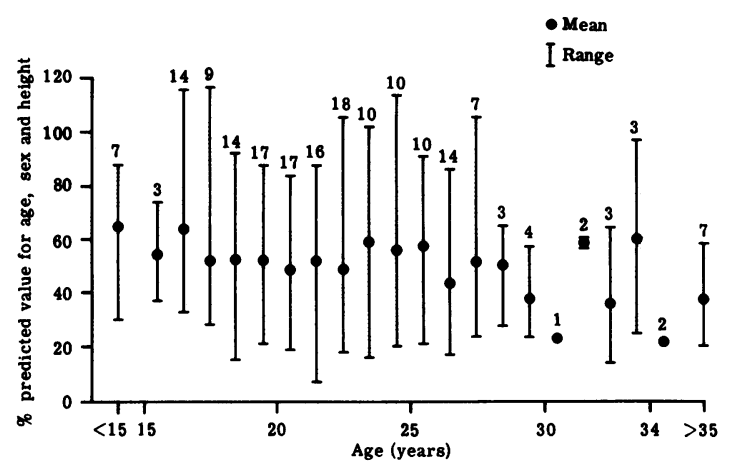

Fig 2 Mean and range of values of FEV $V_{1}$ recorded in 1983 for 191 patients.

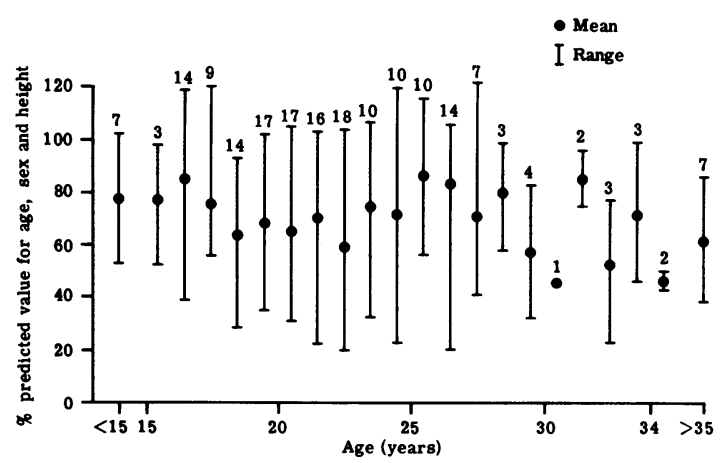

Fig 3 Mean and range of values of forced vital capacity recorded in 1983 for 191 patients.
Table 2 Pathogens isolated from the sputum of 288 patients

\begin{tabular}{|c|c|}
\hline Pathogen & No $(\%)$ of patients \\
\hline $\begin{array}{l}\text { Pseudomonas aeruginosa } \\
\text { Staphylococcus aureus } \\
\text { Haemophilus influenzae } \\
\text { Klebsiella pneumoniae } \\
\text { Mycobacterial species } \\
\text { Aspergillus fumigatus }\end{array}$ & $\begin{array}{r}240(83) \\
172(60) \\
196(68) \\
21(7) \\
7(2) \\
27(9)\end{array}$ \\
\hline
\end{tabular}

the longest follow up had shown remarkably little decline in lung function over more than 20 years; one had shown only a $10 \%$ decline in FEV 1 and FVC, tô $57 \%$ and $70 \%$ predicted respectively, and the other had shown no change in values, which were $57 \%$ and $68 \%$ predicted. The average rate of decline in FEV has been $2-4 \%$ a year for all patients. Some patients? however, showed a sudden dramatic decline of $30 \%$ or more over a few months, often heralding the termi nal illness.

The most common sputum pathogen was Pseudo monas aeruginosa, which affected 240 patients $(83 \%)^{-}$ and was present in every sputum culture in $190(66 \% 8$ (data available on 288 patients). Staphylococcus aureus and Haemophilus influenzae were commono pathogens but were usually isolated from sputun: only intermittently (table 2). Klebsiella pneumoniae was isolated from 21 patients (7\%). Mycobacteria5 infection was seen in seven patients $(2 \cdot 4 \%)$, andB Aspergillus fumigatus was isolated from 27 others (9.4\%). Streptococcus pneumoniae was never isolated? There were no cases of disseminated infection, patho gens being confined to the respiratory tree, and empy음 ema was not seen.

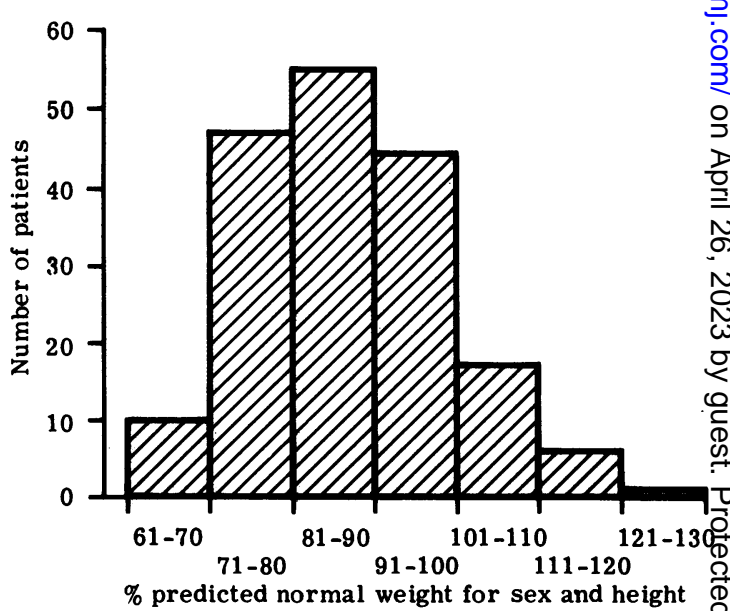

Fig 4 Weight of 180 patients at last follow up in 1983 (no weight records for 15 patients). 
Clubbing of the fingers was present in $278(88 \%)$ of the patients at the last follow up. One hundred and ninety two patients $(62 \%)$ experienced haemoptysis of less than $100 \mathrm{ml}$ but only $30(16 \%)$ of them had a larger haemoptysis, requiring hospital admission (10\% of the total population). Most patients were treated conservatively and none by surgery; in three cases embolisation of the appropriate bronchial artery was performed. Pneumothorax was the most common complication of pulmonary disease $(19 \%)$. It was often recurrent, 61 patients experiencing 133 separate episodes of pneumothorax. Forty seven episodes occurred on the left side, 81 on the right, and five bilaterally. The age at which pneumothorax first occurred ranged from 13 to 38 years but was in the teens for 40 of the 61 patients. Right sided heart failure developed, surprisingly, in only 50 patients $(16 \%)$.

Pulmonary disease was the single most important factor in both morbidity and mortality. It was responsible for $76 \%$ of the 406 admissions to hospital in 1983 and accounted for all but three $(97 \%)$ of the 112 deaths at the Brompton Hospital.

\section{GASTROINTESTINAL DISEASE}

A small number of patients $(11 \cdot 4 \%)$ had no documented symptoms of malabsorption in adolescence. Only 11 patients described severe symptoms of loose offensive stools while taking pancreatic enzyme replacement treatment and other treatment, and for the remainder exocrine pancreatic insufficiency was not a major problem. Most had no dietary restrictions $(51 \%)$ and seven patients were able to stop pancreatic supplements altogether with no ill effects.

Figure 4 shows the weight of surviving patients at their last outpatient visit in 1983. Eighty seven per cent of patients were below their predicted weight.

Small bowel obstruction in adult life, known as meconium ileus equivalent, occurred in 49 cases $(15.7 \%)$, some patients suffering more than one episode. Subacute obstruction producing episodic symptoms of pain, distension, and constipation was seen in 60 cases $(19 \%)$. Most cases were managed conservatively with rehydration, oral and rectal $N$-acetyl cysteine, attention to diet, and enzyme replacement. Other complications encountered were rectal prolapse $(4 \%)$ and intussusception $(1.7 \%)$.

Thirty six individuals (11.5\%) developed diabetes mellitus at ages ranging from 14 to 36 years; 17 patients became diabetic in their teens, three in their 30 s, and the rest in their 20 s. One individual became diabetic seven years before the diagnosis of cystic fibrosis was made. Thirteen patients were insulin dependent but the rest were managed by diet alone or by diet and oral hypoglycaemic agents. None of our patients developed clinical evidence of microvascular complications.

Eighty six patients $(29 \%)$ had clinical hepatomegaly (data unavailable for 19 patients), but fewer had abnormal results in liver function tests $(9 \%)$ and only three developed signs of portal hypertension, with varices and ascites. Splenomegaly was seen in $13 \%$, sometimes unrelated to evidence of liver disease. Gallstones were rare $(1 \cdot 6 \%)$.

\section{OTHER FEATURES}

Hay fever (49 cases, 15.6\%) and eczema (17, 5.4\%) were minor problems in this series, but hypersensitivity to drugs, mainly antibiotics, was quite common, occurring in 76 patients $(24 \%)$. Skin reactions to house dust mite, grass pollen, and other common allergens were seen in $37-47 \%$ of cases, depending on the allergen. If $A$ fumigatus is included, then $221(70 \%)$ of the patients with cystic fibrosis had reactions to at least one allergen. One hundred and fifty five patients $(49 \%)$ had skin reactions to Aspergillus fumigatus, but only $85(27 \%)$ had serum precipitins to this fungus.

Upper airways manifestations of cystic fibrosis took the form of nasal polyps in $76(24 \%)$ and sinusitis. Cutaneous vasculitis was seen in six cases, and renal calculi in five. One patient developed amyloidosis. We have not observed the complications of inappropriate secretion of antidiuretic hormone or severe heat prostration, as reported by Di Sant' Agnese and Davis. ${ }^{6}$

Twenty seven patients $(9 \%)$ developed joint pains, usually in the knees or ankles and usually without redness or effusion. In seven cases this was confirmed as hypertrophic pulmonary osteoarthropathy radiologically, but the remainder had no radiological changes. Symptoms were unrelated to infective exacerbations and generally responded to treatment with minor analgesics or non-steroidal antiinflammatory agents. Refractory cases responded to treatment with corticosteroids.

\section{FERTILITY}

Men with cystic fibrosis are usually infertile owing to failure of development of mesonephric elements, resulting in an obstructive azoospermia. ${ }^{7}$ Twenty five men have requested a semen analysis and all have been azoospermic. Of 133 women over the age of 16 , $13(10 \%)$ had primary amenorrhoea. Menarche was delayed, with an average age of 15.5 years. Ten women have successfully borne children; one woman has had two children. Twenty four women (18\%) subsequently developed secondary amenorrhoea as their general health and weight declined. Twenty eight 
Table 3 Courses of parenteral antibiotics given to 186 patients with cystic fibrosis for Pseudomonas aeruginosa infection, 1965-83

\begin{tabular}{lc}
\hline Antibiotic regimens & No of courses \\
\hline Gentamicin and carbenicillin & 401 \\
Tobramycin and carbenicillin & 39 \\
Gentamicin or tobramycin with: & 55 \\
piperacillin & 33 \\
azlocillin & 28 \\
ticarcillin & 19 \\
ceftazidime & 15 \\
Ceftazidime alone & 12 \\
\hline
\end{tabular}

Table 4 Antibiotics given by aerosol to 131 patients with cystic fibrosis for chronic Pseudomonas aeruginosa infection

\begin{tabular}{ll}
\hline Antibiotic regimen & No (\%) of patients* \\
\hline Gentamicin and carbenicillin & 78 \\
Colomycin & 42 \\
Gentamicin & 34 \\
Carbencillin & 24 \\
Tobramycin & 1 \\
Others & 6 \\
\hline
\end{tabular}

*Some patients have used more than one regimen at different times.

women were using oral contraceptive pills containing $50 \mu \mathrm{g}$ of oestrogen and there have been no unplanned pregnancies or side effects.

\section{SOCIAL AND FAMILY MATTERS}

The social class of patients seen at the Brompton Hospital Cystic Fibrosis Unit, as defined by father's occupation, shows a strong bias to the higher social classes, $56 \%$ being of social class I or II. As many as $123(39 \%)$ of our patients had a sibling with cystic fibrosis and a quarter of these had experienced the death of a sibling with the disease. The incidence of cystic fibrosis among all the siblings of all our inde $\overrightarrow{\mathrm{F}^{\prime}}$ cases was $26 \%$, very close to the $1: 4$ predicted for an autosomal recessive condition.

Only $17 \%$ of patients thought that illness ha需 severely curtailed their schooling, and the level of educational achievement was high; 161 (51\% patients left school with some GCE or CSE passes, and $12 \%$ went on to higher education.

Most patients remained single, usually living with their parents, but $41(13 \%)$ were married. Most werg employed or in full time education or were house wives; only $13 \%$ were unemployed for reasons of health.

\section{HOSPITAL ADMISSIONS AND TREATMENT}

Of the 195 patients surviving to the end of $1983,10 \Phi$ were admitted to hospital during 1983, with an aver= age of 3.7 admissions per patient for that year. Most of the 406 admissions were for deterioration in lung function or other respiratory complications. Fifty patients had never been in hospital in their liveso Even though patients had to travel considerable distances-from as far away as Cornwall, Wales, anळ Lanarkshire-over $85 \%$ of hospital admissions were to the Brompton rather than local hospitals. Patient who became suddenly ill were often transferred afte? initial treatment.

Patients chronically infected with Ps aeruginos $\overrightarrow{\vec{\oplus}}$ and admitted to hospital with deteriorating lung func 3 tion were treated with 10 day courses of parenteraf antibiotics, usually an aminoglycoside combined with. an antipseudomonal penicillin. Table 3 shows the antibiotic regimens used over the period of the study을 gentamicin combined with carbenicillin was the stan dard regimen for many years but recently newer penio

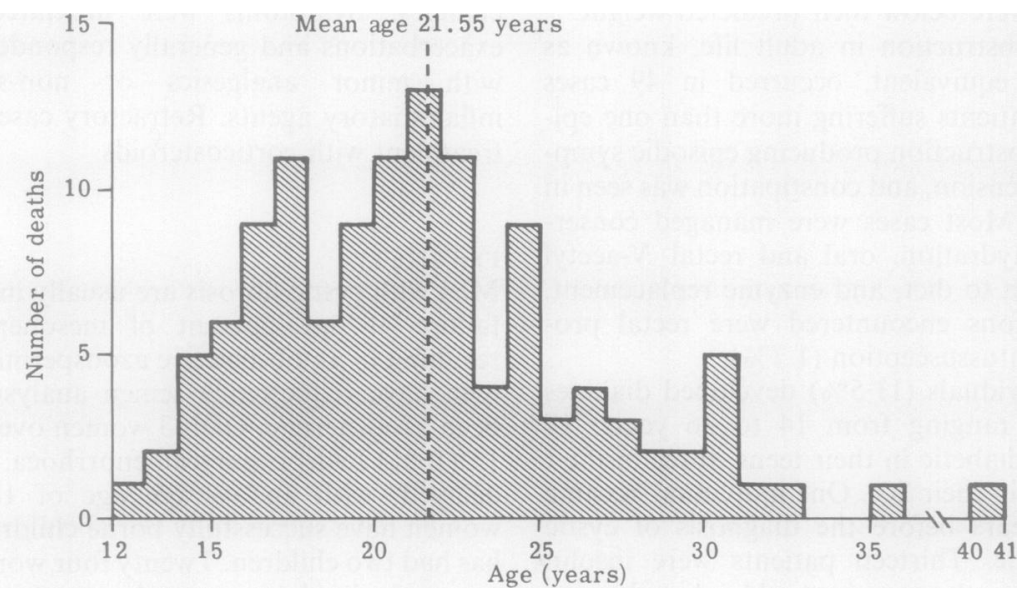

Fig 5 Age of 121 patients at the time of death. 
cillins and cephalosporins have been used. One hundred and thirty one patients with chronic pseudomonas infection, who were being admitted to hospital frequently, have been given long term treatment with antibiotics delivered by aerosol. Table 4 shows the antibiotic regimens used. Side effects have been rare-no patient reported an aggravation of wheeze; one developed a rash, and three complained of sore throat without evidence of candidiasis. All sputum cultures from 43 individuals were reviewed for the time that they received aerosol gentamicin and carbenicillin, up to five years in some cases. Strains of Ps aeruginosa isolated were often reported as "resistant" to either gentamicin $(26 \%)$ or carbenicillin (37\%) transiently, but they always reverted to full sensitivity without cessation of aerosol treatment. $^{8}$

$S$ aureus and $H$ influenzae infections were treated with prolonged courses of oral antibiotics. Amoxycillin or ampicillin was the first choice for $H$ influenzae (304 patients received one or more courses), with chloramphenicol (109) or cotrimoxazole (123) the main second line drug. Flucloxacillin or cloxacillin was the first choice drug in $S$ aureus infection (303 patients), with erythromycin (81) and fusidic acid (25) as alternatives.

Bronchodilators have been given at some stage to $224(71 \%)$ of the patients, either by metered dose inhaler or by nebuliser, although reversible airflow obstruction was demonstrated in far fewer cases. No patient complained of a worsening of symptoms. Corticosteroid treatment was given to 82 patients, usually when they were terminally ill.

\section{SUR VIVAL}

One hundred and twenty one patients (38\%) have died and details of the cause of death were available for the 112 who died at the Brompton Hospital. Pulmonary disease was the major cause of death $(97 \%)$; of these 109 deaths, most were due to respiratory infection, but 15 died with a pneumothorax and three with severe haemoptysis. Right heart failure was present at the time of death in $31(29 \%)$. Meconium ileus equivalent and its complications were responsible for the three remaining fatalities. The mean age at death was 21.6 years. Figure 5 shows the distribution of deaths by age. The mean age of the 195 surviving patients attending the unit in December 1983 was 22.9 years, the oldest patient being 61 .

\section{Discussion}

This is by far the largest series of adult patients with cystic fibrosis yet reported. Di Sant'Agnese and Davis reported 75 cases from the United States in $1979^{6}$ and reviewed the other major series published at that time; other series include 70 cases from the United States, ${ }^{9}$ 31 cases from Australia, ${ }^{10}$ and 45 cases from this hospital previously reported. ${ }^{11}$ The male predominance among adults with cystic fibrosis has been noted before but it was not as striking in this present series as in earlier ones. ${ }^{910}$ One of the major differences between the present series and others is that all patients were referred to us and therefore by definition were selected as having survived to the age of 16 years, whereas patients in most other series have been followed continuously by their paediatric centre. The low incidence of meconium ileus as a presenting feature is one reflection of this selection. There was a significant difference in the age at diagnosis of those presenting with gastrointestinal symptoms and the group with respiratory symptoms only. This difference may be due to the fact that gastrointestinal symptoms in infancy attract medical attention, or may imply that patients with a lesser degree of malabsorption have a better prognosis, as suggested by Gaskin and colleagues. ${ }^{12}$

The milder degree of malabsorption in adults with cystic fibrosis than in children has been noted previously ${ }^{611}$ and may be due in part to adaptive responses of some gut regulatory peptides. ${ }^{13} \mathrm{An}$ acid stable lingual lipase is also responsible for some lipolysis in cystic fibrosis ${ }^{14}$; possibly this becomes more active in adult life. We did not observe any clinical evidence of the microvascular complications of diabetes mellitus in our patients; this may be due to the shorter survival of patients with cystic fibrosis than of other diabetics. There is evidence that the thickness of the capillary basement membrane is increased in all patients with cystic fibrosis, particularly those with hyperglycaemia, as it is in other patients with diabetes mellitus. ${ }^{15}$

Studies on the endocrinology of amenorrhoea in cystic fibrosis and the metabolism of contraceptive steroids by women with cystic fibrosis have been performed in our unit. ${ }^{16}$ Amenorrhoea is related to low body weight and to a low percentage of body fat and the resultant oestrogen deficiency, as in anorexic women. Women with cystic fibrosis handle contraceptive steroids normally and $30 \mu \mathrm{g}$ oestrogen pills provide adequate contraception. There is no need to adjust the dose during infective exacerbations or oral antibiotic use.

Over half of our patients were in social class I or II according to their father's occupation, compared with an expected proportion of about $20 \%$. This may reflect the type of patients who seek to be referred to a national centre and are able and prepared to travel to it. The educational achievements and work record of patients with cystic fibrosis, sometimes despite severe pulmonary disease, is a great credit to their motivation. 
Pulmonary disease dominates the clinical picture in the older patient with cystic fibrosis. There is an extensive literature on the treatment of acute infective exacerbations of disease due to Ps aeruginosa using parenteral antibiotics. ${ }^{17}$ Our experience with long term aerosol chemotherapy, first reported in $1981,{ }^{18}$ has been extended to 78 patients, gentamicin and carbenicillin having been used for up to five years without problems of antibiotic resistance or serious side effects. Such treatment is expensive and time consuming for the patient and is at present reserved for individuals whose condition is rapidly deteriorating and who require frequent hospital admission. Pneumothorax had a higher incidence in this series than the $2-7 \%$ reported in children; the management of this problem has recently been reviewed, ${ }^{19}$ the dangers of prolonged intercostal drainage and the relatively good results of surgical intervention being emphasised. Prednisolone has not been shown to be of benefit in patients with stable airflow obstruction, ${ }^{20}$ but the effect of corticosteroids on those with a reversible element of airflow obstruction has not been studied.

Experience in other parts of the world suggests that patients with cystic fibrosis do better when cared for in specialised units during childhood. ${ }^{21}$ Such units can provide a concentration of knowledge and experience of the disease among all types of health worker. It is generally accepted that other conditions requiring specialist expertise, such as haemophilia and childhood leukaemia, should be treated in specialist centres; and it therefore seems logical that if further improvements in the prognosis of cystic fibrosis are to be made specialised care should be provided. With the increasing numbers of patients now surviving into adult life, together with the social and economic costs of travel to a distant centre, it is hoped that in future thoracic physicians in an appropriate number of regional cardiothoracic centres will take up the challenge of cystic fibrosis.

We are indebted to all colleagues who have referred patients to us. We would also like to thank Dr M Walport, Dr M Richards, the late Dr Glyn Morgan, Sister F Duncan, and Mr A Duncan, who have assisted in the laborious task of collection and storage of data. Miss S Hockley typed this manuscript and all the questionnaires. The computer program is the work of the computer unit at the Brompton Hospital, and in particular Mr S Saunders. ARLP was supported by the Frances and Augustus Newman Foundation, and AW is supported by a grant from the Cystic Fibrosis Research Trust.

\section{References}

1 Wood RE, Boat TF, Doershuk CF. State of the art: cystic fíbrosis. Am Rev Respir Dis 1976;113:833-78.

2 Hunt B, Geddes DM. Newly diagnosed cystic fibrosis in middle and later life. Thorax 1985;40:23-6.

3 Gibson LE, Cooke RE. A test for the concentration of electrolytes in sweat in cystic fibrosis of the pancreas utilising pilocarpine by iontophoresis. Pediatrics 1959;23:545-9.

4 Society of Actuaries. Build and blood pressure study Part I. Chicago: Society of Actuaries, 1959:16.

5 Cotes JE. Lung function: assessment and application in $\vec{P}$ medicine. Oxford: Blackwell Scientific Publications, 1979.

6 Di Sant'Agnese PA, Davis PB. Cystic fibrosis in adults 75 cases, and a review of 232 cases in the literature $x$ Am J Med 1979;66:121-32.

7 Stern RC, Boat TF, Doershuk CF. Obstructive azoospermia as a diagnostic criterion for the cystic fibrosiơ syndrome. Lancet 1982;i:1401-3.

8 Penketh ARL. Bronchopulmonary infection with Pseudo읙 monas aeruginosa in cystic fibrosis. MD thesis, London University, 1984.

9 Shwachman H, Kowalski N, Kahw KT. Cystic fibrosis, new outlook. 70 patients above 25 years of age. Medicine (Baltimore) 1977;56:129-49.

10 Gracey M, Anderson CM. Cystic fibrosis of the pancreas in adolescence and adulthood. Aust Ann Med 1969;18:91-101.

11 Mitchell-Heggs P, Mearns M, Batten JC. Cystic fibrosis in adolescents and adults. $Q J$ Med 1976;179:479-504일

12 Gaskin K, Gurwitz D, Durie P, Corey M, Levison $\mathrm{H}_{\mathbb{P}}$ Forstner G. Improved respiratory prognosis in patients with cystic fibrosis with normal fat absorp $\vec{B}$ tion. J Pediatr 1982;100:857-62.

13 Allen JM, Penketh ARL, Adrian T, et al. Adults cystie fibrosis: post-prandial response of gut regulatory. peptides. Gastroenterology 1983;85:1379-83.

14 Fredrikzon B, Blackberg L. Lingual lipase: an importan lipase in the digestion of dietary lipids in cystio fibrosis? Pediatr Res 1980;14:1387-90.

15 Rodman HM, Matthews LW. Hyperglycaemia in cystic fibrosis: a review of the literature and our own experience. In: Warwick WJ, ed. 1000 years of cystic fibrosis Minneapolis: University of Minnesota, 1981:67-76. ₹

16 Stead RJ, Hodson ME, Batten JC, Adams J, Jacobs HSO Amenorrhoea in cystic fibrosis. Clin Endocrinol (in press).

17 Batten JC, Matthew DJ. The respiratory system. In Hodson ME, Norman AP, Batten JC, eds. Cystion fibrosis. London: Baillière Tindall, 1983:105-31.

18 Hodson ME, Penketh ARL, Batten JC. Aerosol ca benicillin and gentamicin treatment of Pseudomonoss aeruginosa infection in patients with cystic fibrosi Lancet 1981;ii:1137-9.

19 Penketh ARL, Knight RK, Hodson ME, Batten J Management of pneumothorax in adults with cyste fibrosis. Thorax 1982;37:850-3.

20 Stead RJ, Pantin CFA, Hodson ME, Batten JC. Preo5 nisolone in the treatment of airflow obstruction if adult patients with cystic fibrosis. Thorax 1985;40:21

21 Warwick WJ. Prognosis for survival with cystic fibrosis the effects of early diagnosis and cystic fibrosis cent远 care. Acta Pediatr Scand 1982;301(suppl):27-31. 